\title{
Experimental Investigation the Effect of Air Injection on Performance and Detection of Cavitation in the Centrifugal Pump Based on Vibration Technique
}

\author{
Dr. Ahmed Ramadhan Al-Obaidi ${ }^{1} \quad$ Prof. Rakesh Mishra ${ }^{2}$ \\ ${ }^{1}$ Department of Mechanical Engineering, Faculty of Engineering, Mustansiriyah University, \\ Baghdad, Iraq \\ ${ }^{2}$ Department of Engineering and Technology, School of Computing and Engineering, \\ University of Huddersfield, UK \\ Corresponding author E-mail: ahmedram@uomustansiriyah.edu.iq
}

\begin{abstract}
Cavitation is a problem that occurs in any pump and contributes highly towards the deterioration in the performance of the pump. In industrial applications, it is vital to detect and minimize the effect of cavitation in pumps. The use of various techniques, such as vibration analyses, can provide a more robust detection of cavitation in the pump. In this work, the effect of air injection at the inlet of the pump on its performance has been focused by detecting and diagnosing the cavitation using vibration technique. The results obtained for vibration signal in time and frequency domains were analysed in order to achieve a better understanding regarding detection of cavitation. The effects of different operating conditions related to the cavitation were investigated in this work using different statistical features in time domain. Moreover, Fast Fourier Transform technique for frequency domain was also applied. The results showed that there is no significant change between both cases (with and without air injection) when the pump works under low flow operating conditions. However, there is a slight difference between both cases after 300(1/min) and drop in the pump head for air injection was noticed as compared to without air injection condition. Moreover, the development of cavitation starts at higher design flow and it will increase when flow rate is increased more than $350(1 / \mathrm{min})$. The trend of vibration signal amplitude was more random with high peaks when compared with normal operating conditions (without cavitation).
\end{abstract}

Keywords: Centrifugal pump, Cavitation, Air injection, Vibration technique, Time and frequency domains 


\section{Introduction}

Centrifugal pumps play an important role in engineering applications since they are commonly used in industrial and residential systems, covering wide range of flow rates. Improving the performance of turbomachines such as the centrifugal pumps can be difficult to achieve, since the flow is turbulent with unsteady behaviour and cavitation. Cavitation is a complex phenomenon that is commonly considered as one of the main causes of deterioration in pump performance. Diagnosing cavitation and detecting its level of severity are essential for maintaining the pump's reliability. Continuous condition monitoring of the pump is important to increase its operational life, decrease maintenance costs and hence, enhance the reliability of the pump [1-3].

The vibration in centrifugal pumps might occur from various types of sources, comprising of hydraulic and mechanical excitation forces. These results in an increase in vibration levels that may decrease the performance of the pump and lead to damage in the pump parts, such as the impeller and volute. This also leads to a decrease in pumps bearing life and seal failures [4]. Hydraulic sources of vibration in a pump includes blades passing forces, hydraulic imbalance, recirculation flow, cavitation, system instabilities, water hammer and so on [5]. There are various kinds of physical processes that create vibration within a pump, such as hydraulic interaction with the piping system, improper installation or maintenance, application for the pump, manufacturing designs and different types of faults [6]. Typically, the mechanical vibration sources in the pump generates from several sources such as pressure fluctuations created in the fluid, imbalance, misalignment between shafts connections and damaged bearings [7]. Many researchers have attempted to experimentally investigate the pump performance with and without cavitation using various conditioning monitoring methods. One of these studies done by Chudina [8] used noise as an indicator in investigating cavitation within the centrifugal pump. The author carried out analysis of the noise signal in frequency domain under different operating conditions. The results showed that the cavitation increases at high flow rate particularly at the high range of frequency. Cernetic [9] detected and monitored of cavitation in the pump by using vibration and noise signals. The results have shown that pump has various spectra, vibration and noise levels with various discrete frequencies. In addition, they have found that the difference between vibration and noise under cavitation and non-cavitation conditions was between 10 to $15 \mathrm{~dB}$. Later, Čdina [10] detected cavitation in the centrifugal pump using the sound signal from the microphone. They have experimentally studied the centrifugal pump to investigate the sound level due to cavitation 
under different discharge flow rates. Their results showed that when cavitation becomes fully developed, the sound level goes to a higher level compared without cavitation. The noise occurrence on the pump depends on the flow rate, speed of the pump and the instability of the pump. Čudina and Prezelj [11] detected the cavitation in pump using discrete audible spectra frequency. The results of their study have shown that the spectrum of the discrete frequency audible noise was related with inception and development of cavitation within a pump. Also, the level of the spectra frequency peak was increased with the inception of cavitation which further increased with the development of the cavitation and it reached to a maximum value when the cavitation process was fully developed. Nasiri et al. [12] analysed the vibration signal for detecting cavitation phenomena in centrifugal pumps by using neural networks. They have introduced three monitoring conditions such as normal, developed and fully developed cavitation in the pump. In order to test such network, they used the feed forward back propagation. Their finding revealed the reliability of the method to detect cavitation in the pump. Study of cavitation connected to centrifugal pump appears highly complex due to its cause's reduction in efficiency, turbulent flow structure, vibration, noise, and erosion. In the current study, the focus is to detect cavitation under different operating conditions using vibration analysis technique, as it is the effective tool to investigate the occurrence of vapour bubble and flow pattern in the pump [13-15]. Zhang et al. [16] studied the effect of slope volute for cavitation in centrifugal pump using vibration characteristics. They used three operating conditions including at best effectincy point (BEP), 80\% from BEP and 90\% from BEP. They noticed that the vibration amplitude signals were more non-uniform due to the cavitation conditions. That's mean because of the insufficient for bubbles to collapse near the inlet impeller. Buono et al. [17] investigated the pump fault diagnosis and cavitation monitoring using vibration analysis. The characterization of experimental test was permitted for comparing pressure ripple through varying calibrated orifices diameter. They observed that the ripple amplitudes increase as the no cavitating orifice decreased, this was another significant influence due to cavitation. Casoli et al. [18] analysed the vibration signal-based on fault identification and classification in piston pump. The signals of vibration were exploited and acquired in order to extract different features analysis for detect fault identification. Obtained features have been decreased to reduce the computational effort. Results show the capability of vibration analysis to recognize that fault happened in the pump for each operating condition. Lu et al. [19] detected flow state in the centrifugal pump using vibration method. They found that in the centrifugal pump, can detect different problems such as unstable flow occurrence, backflow, rotating stall and cavitation through applying analysis vibration signals in order to 
find safe steady conditions in the system. Mousmoulis et al. [20] monitored and diagnostic cavitation in the centrifugal pump based on vibration approach. Using the vibration signals measurements in domains of time and frequency were capable to detect the cavitation appearance. Outcomes also display that the sensor location and the characteristics of acquisition undoubtedly influence the cavitation detection. In the current experimental measurement study, vibration technique based on different pump operation conditions with and without air injection were used in order to simultaneously find the relationship between vibration signal and cavitation within a pump. This is for the purpose of detecting cavitation within the centrifugal pump. In this work, the sources of pump vibration during different operational conditions were evaluated. Further to this, explanations of how the inception and development of cavitation influences the pump vibration level were provided. This study includes the analysis of vibration signals in the time domain format using time waveform analysis (TWFA), followed by various statistical features to predict and diagnose cavitation under various operating conditions. For further analysis on the characteristic of cavitation inside the pump, the vibration signal in time domain is converted to frequency domain by employing the Fast Fourier Transform technique. This is for the purpose of predicting cavitation. This study further focuses on analysing the vibration signal in frequency domain based on different range of frequencies. Furthermore, analyses on the vibration amplitude in frequency domain by using different features, such as mean and RMS on the vibration amplitude values were also carried out. This analysis is essential in order to obtain a better understanding and gain more information regarding the detection of the occurrence of cavitation for various frequency ranges and hence, finding the sensitive frequency range for predicting cavitation.

\section{Experimental Setup for the Centrifugal Pump}

When cavitation occurs in the different types of machines (e.g. propellers, turbines and various kinds of pumps), it leads to drop in pressure, particularly at the eye of impeller [21]. As a result, it leads to an increase in the level of noise and vibration, which causes an increase in pressure fluctuations within a pump. When cavitation starts to occur within the pump, the formation of bubbles takes place [22-23]. As cavitation continues, the bubbles collapse close to the surface of the impeller, which eventually erodes the impeller and causes pitting on the surface of the impeller and volute [24]. Since the formation and collapse of bubbles happens randomly, the inception and development of cavitation can cause high noise and vibration [25]. The detection 
of cavitation experimentally was carried out by using accelerometer. To achieve this aim experimentally, it was essential to construct and design an appropriate experimental setup for the centrifugal pump. The designing of this experimental setup will be discussed in more details in the next section. Figure 1 depicts the different parts for the flow loop system of the centrifugal pump. The centrifugal pump can supply water to the tank with a maximum pressure of about 10bar. The selected flow loop system was re-circulatory and included a plastic water tank, PVC clear pipes and PVC connections components. The inlet pipe diameter of the pump was 2 inches. Also, the outlet pipe diameter of the pump used was 1.25 inches. Thus, a reducing coupling of 1.25 to 1.5 inches was used to connect the outlet pipe to the water flow meter line. The tank was made of plastic with dimensions of $95 \times 90 \times 110 \mathrm{~cm}$, the reason behind that is to permit observation when the cavitation occurs.

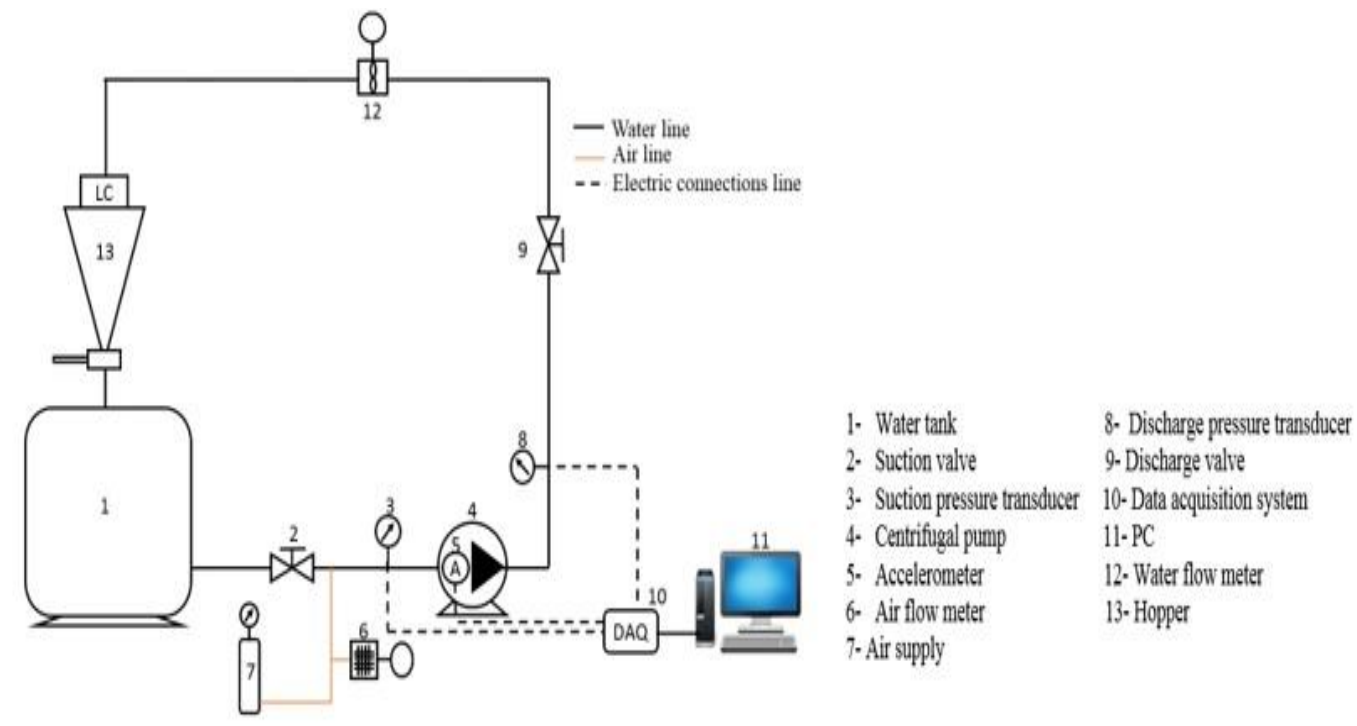

Figure1: Components of Experimental setup for flow loop system

\subsection{Effect of Different Amounts of Air Injection in the Centrifugal Pump}

Investigating the various degrees of cavitation within the centrifugal pump in this section was carried out by studying the effect of air injection into the suction side of the pump. To simulate various cavitation flows based on different operation condition, air injection was used. It can be controlled either by air injection through the pressure supply by the air valve at the suction side of the centrifugal pump where the quantity of air injection can be measured by using air flow meter FMA 1700/1800 series from OMEGA Engineering INC was chosen for this study. In this experimental measurement, different amounts of air are injected into the suction side of the pump. Also, the pump was tested under various flow rates starting from to $100(1 / \mathrm{min})$ to 
$370(1 / \mathrm{min})$ corresponding to different operation conditions (low flow rate) and cavitation conditions (high flow rate). For this experimental work, higher amounts of air cannot be injected within the suction pipe. There are two possible reasons behind this, the first being due to the high injection of air this cause's unstable flow within the suction pipe and the pump, this leads to a rapid decrease in the performance of the pump and the second reason is the high air injection causes clogging at the inlet of the pump. Table 1 shows the parameters study.

Table 1: Flow rate operating conditions in the pump at varaty of air injections

\begin{tabular}{|l|l|l|l|l|l|l|l|l|l|l|l|l|l|l|l|l|}
\hline \multicolumn{10}{|c|}{ Flow rate } \\
\hline 378 & 370 & 365 & 362 & 352 & 342 & 331 & 320 & 310 & 302 & 276 & 252 & 227 & 200 & 177 & 152 & 103 \\
\hline \multicolumn{10}{|c|}{ Air injection (1/min) } \\
\hline \multicolumn{10}{|c|}{1} & \multicolumn{10}{|c|}{1.8} \\
\hline
\end{tabular}

\subsection{Performance Output of the Centrifugal Pump under Air Injection}

The one important aim of this experimental study is to calculate the pump head. Therefore, several experimental measurements were conducted to find the pump performance under various air injections.

\subsection{Calculated Head of the Centrifugal Pump at 0.4(1/min) Air Injection}

Figure 2 depicts the pump head under different experimental flow rates with and without air injection. The amount of air injection in this case was $0.4(1 / \mathrm{min})$ and $\mathrm{N}=2755 \mathrm{rpm}$. It is evident that the head under both cases (with and without air injection) in the pump has a continuous downward trend with increasing flow rate. In addition, the results showed that there is no significant change between both cases when the pump works under operating conditions between 150 and 300(1/min). However, it can be seen that there is a slight difference between both cases after $300(1 / \mathrm{min})$ and drop in the pump head for air injection was noticed as compared to without air injection condition. 


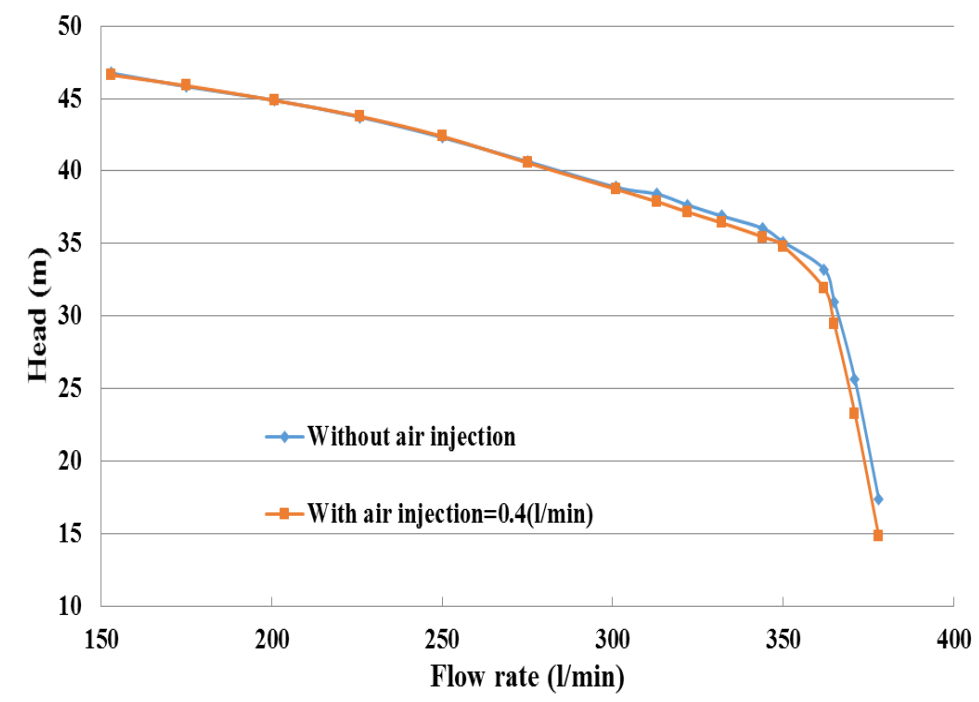

Figure 2: Head of the centrifugal pump with and without air injection at 2755rpm, and air injection $0.4(1 / \mathrm{min})$

Earlier detection of cavitation in the centrifugal pump, under different air injections is through the use of vibration technique. It is essential to first investigate and calculate Net Positive Suction Head (NPSH) of the centrifugal pump and then relate it with the different flow rates and air injection. The cavitation characteristics of the pump that were monitored as an important part of this study was plotted in Figure 3. This figure depicts the Net Positive Suction Head Available (NPSHA) and Net Positive Suction Head Required (NPSHR) against different flow rates regarding the inception and development of cavitation in the pump with air injection of $0.4(1 / \mathrm{min})$. To achieve this purpose, the pump flow rate can be changed through progressively throttling the discharge valve and keeping the suction valve fully open (100\%) whilst keeping the pump rotational speed constant at $2755 \mathrm{rpm}$. From this figure, it can be clearly observed that when the pump operates under low flow rate, no cavitation occurs. This is due to the NPSHA being higher than the NPSHR. However, at flow rate greater than $300(1 / \mathrm{min})$, cavitation occurs in the pump then the intersection between both curves (NPSHA and NPSHR) occurs at flow higher than 350(1/min). That means the development of cavitation starts at this point and it will increase when flow rate is increased more than $350(1 / \mathrm{min})$ therefore, at this stage the NPSHA is smaller than the NPSHR. 


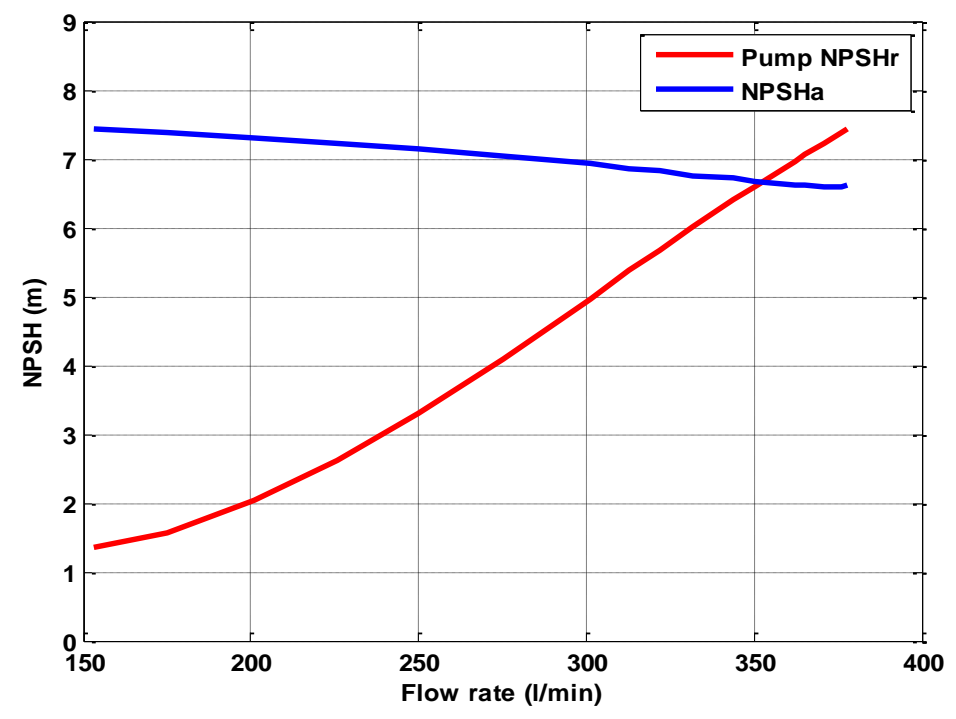

Figure 3: The cavitation characteristics of the pump under different flow rates and air injection $0.4(1 / \mathrm{min})$

\subsection{The Vibration Signal Analysis Based on Time Domain under Amount of Air Injection of $0.4(1 / \mathrm{min})$}

Figure 4 depicts the vibration signal waveform for the pump in time domain obtained at $0.4(1 / \mathrm{min})$ air injection rate. These signals are collected at $\mathrm{N}=2755 \mathrm{rpm}$ and under various flow rate conditions (under normal and cavitation conditions) studied in this experimental test. As seen from this figure, the different levels of the vibration amplitudes depend on the various flow rates. It can be seen that when the pump works under low flow rate, for instance between 150 and $300(1 / \mathrm{min})$, the levels of vibration amplitudes are lower than when the pump is operating under high flow rate resulting in the vibration amplitude signal being increased as flow rate is increased due to three possible reasons. The first is due to air injection within a pump. The second is due to the high interaction between the impeller and volute tongue region and the final reason, which is the most important, is due to the occurrence of cavitation at the high flow rate. It can be clearly seen that there are different levels of vibration amplitudes when the pump operates at normal conditions (without cavitation) and under cavitation conditions with air injection. In this case, the trend for the vibration amplitude was more random with high peaks when compared with normal operating conditions. By comparing these figures, it can be concluded that the vibration signals are sensitive to predict cavitation with air injection within a pump. 

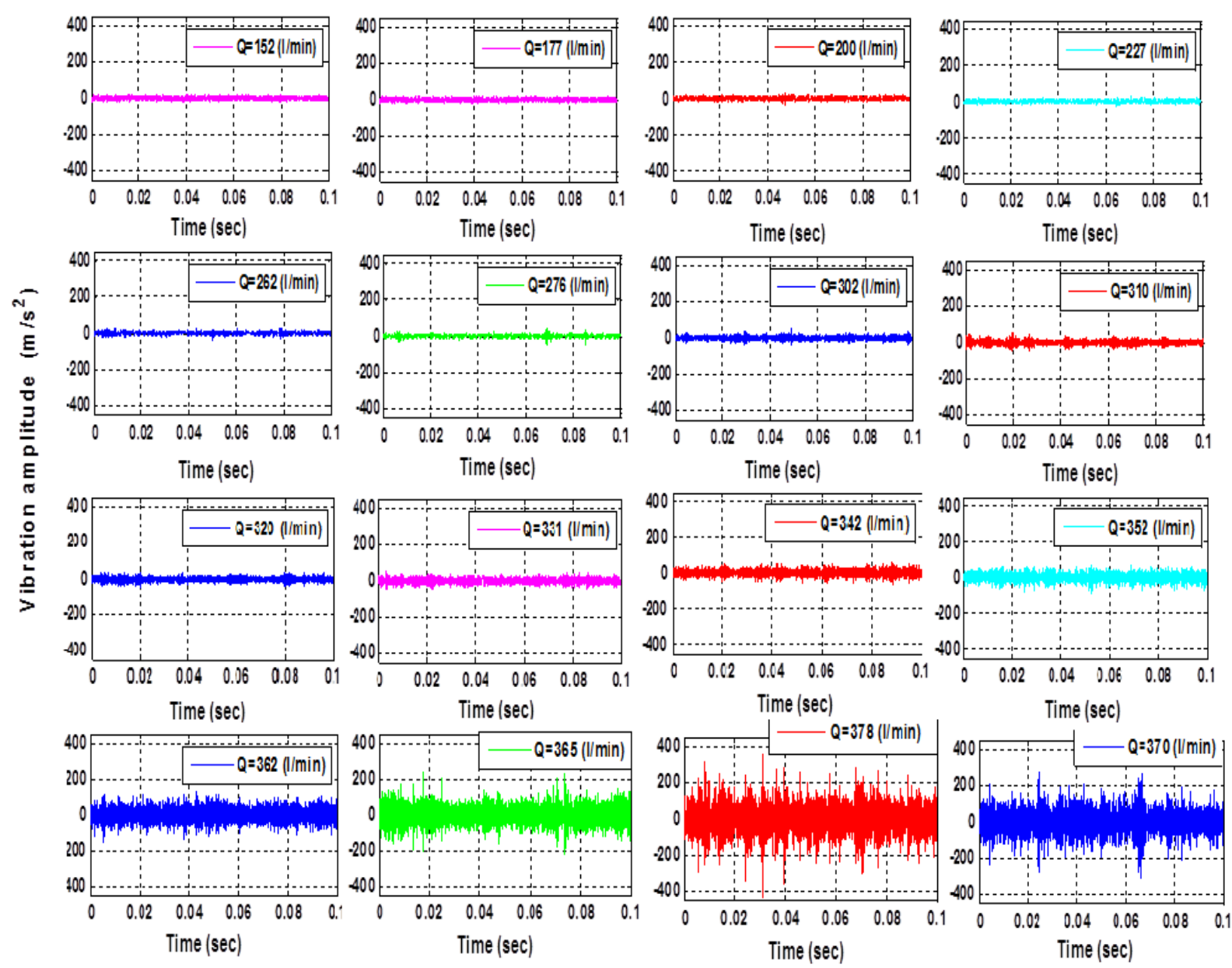

Figure 4: Analysis of the vibration signal in TWFA at $\mathrm{N}=2755 \mathrm{rpm}$ and air injection of

\section{$0.4(1 / \mathrm{min})$}

\subsection{Analysis of the Vibration Signal Based on Time Domain at 0.4(1/min) Rate of Air Injection}

Further analysis on the vibration signal in time domain, with and without air injection was conducted in this section using the same different statistical features which were used in previous sections which include peak, RMS, peak-to-peak and variance features. Figure 5 depicts the analysis on the vibration signals for the centrifugal pump, using the abovementioned features at different flow rates, air injection at $0.4(1 / \mathrm{min})$ and $\mathrm{N}=2755 \mathrm{rpm}$ operational conditions. It can be seen from this figure (with and without air injection) that there is a small indication of variance in the vibration level at flow rates below $350(1 / \mathrm{min})$. However, the results from experimental measurements revealed that these statistical features of vibration signals have the same trend under the different flow rates. The vibration level witnesses a significant rapid increase when the pump operates at flow rate higher than $350(1 / \mathrm{min})$. It can 
be observed that the trends for the vibration signals using peak and peak-to-peak features with air injection, starts to ascend before the trends for the vibration signals without air injection at flow rate higher than $340(1 / \mathrm{min})$. The reason for this is due to the effect of the air injection in a pump and the occurrence of cavitation at high flow rate, which causes more unstable flow within a pump. It is noticed that the use of peak and peak-to-peak features were more sensitive to investigate the effect of air injection when compared to RMS and variance features. The experimental results showed that the analysis of variation in the level of vibration amplitudes in a pump, under different experimental flow rate measurements, with and without air injection in time domain, agreed with the characteristics of cavitation that was depicted in Figure 3.
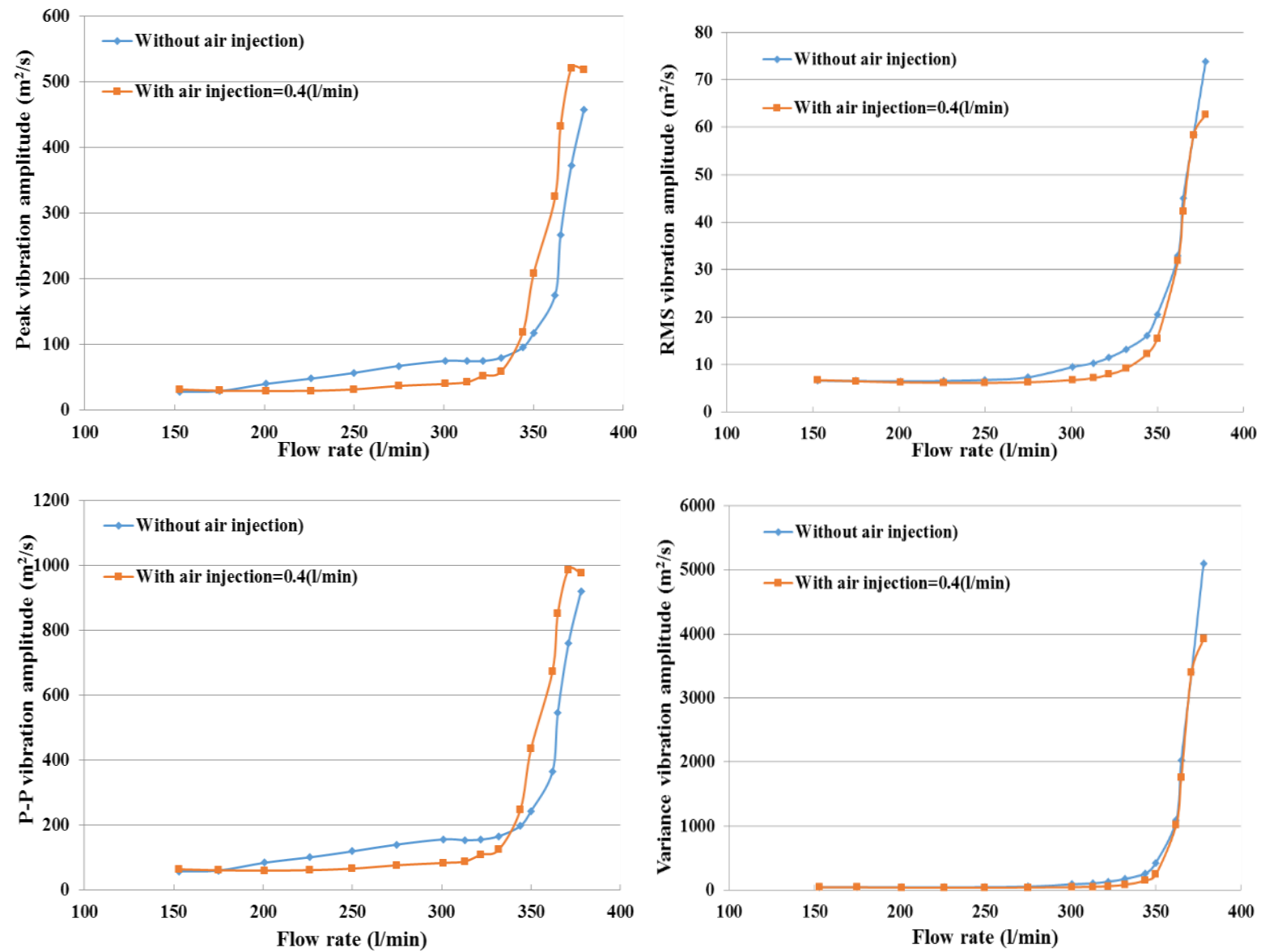

Figure 5: Trends of peak, RMS, peak to peak and variance values of the vibration signal at $2755 \mathrm{rpm}$ with and without air injection

\subsection{Analysis of the Vibration Signal Based on Frequency Domain at $0.4(1 / \mathrm{min})$ Rate of Air Injection}

Frequency domain analysis was carried out under different air injection rates in order to investigate the changes in the level of vibration amplitude. Figure 6 depicts the analysis on the 
vibration signal under the different ranges of frequencies (a) $0 \mathrm{~Hz}-1 \mathrm{kHz}$ and (b) $1 \mathrm{kHz}-2 \mathrm{kHz}$ ) at various flow rates, $\mathrm{N}=2755 \mathrm{rpm}$ and air injection of $0.4(1 / \mathrm{min})$. Different types of frequencies were observed to have appeared. The first was the rotational frequency of $45.91 \mathrm{~Hz}$, whilst the second was the Blade passing frequency (BPF) $229.5 \mathrm{~Hz}$ and their harmonics. It can be seen that the vibration amplitude increases as flow rate increases due to the occurrence of the inception and development of cavitation in the pump and also due to the effect of air injection within a pump.

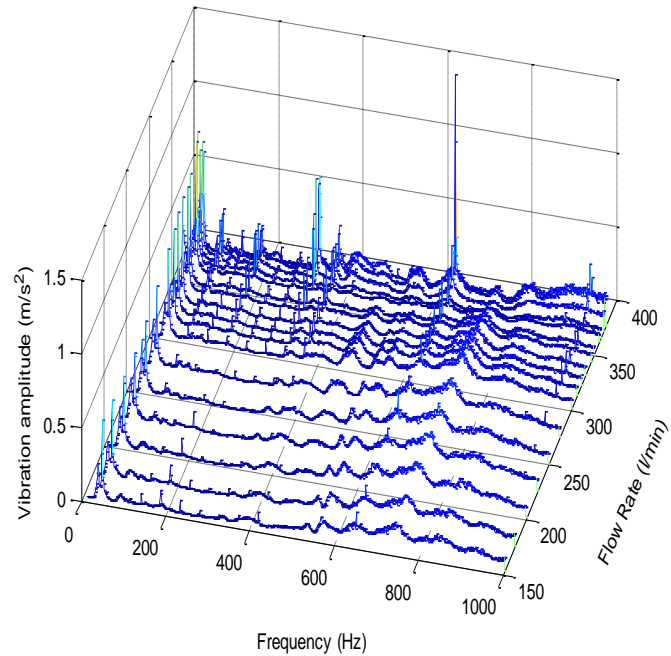

(a) $0 \mathrm{H}-1 \mathrm{kH}$

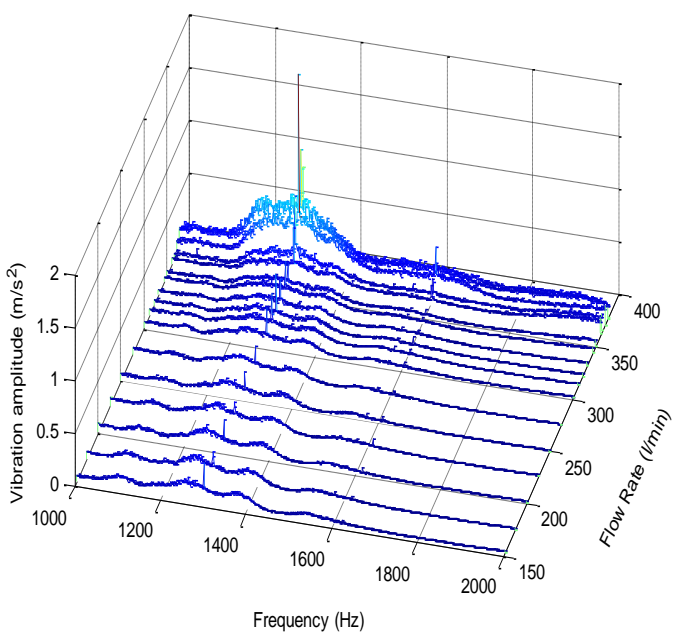

(b) $1 \mathrm{kH}-2 \mathrm{kH}$

Figure 6: Vibration signal in frequency domain at various flow rates with the frequency range from (a) $0 \mathrm{~Hz}-1 \mathrm{kHz}$ to (b) $1 \mathrm{kHz}-2 \mathrm{kHz}$ at $2755 \mathrm{rpm}$ and air injection of $0.4(1 / \mathrm{min}$ )

Figure 7 depict using mean and RMS vibration amplitude features, with and without air injection to analyse the vibration signal in frequency domain. These features were investigated under different range of frequencies which include a) $0 \mathrm{~Hz}-1 \mathrm{kHz}$, b) $1 \mathrm{kHz}-2 \mathrm{kHz}$, c) $2 \mathrm{kHz}-$ $10 \mathrm{kHz}$, and d) $10 \mathrm{kHz}-15 \mathrm{kHz}$, at different flow rates, air injection of $0.4(1 / \mathrm{min})$, and $\mathrm{N}=2755 \mathrm{rpm}$ operational conditions. It can be observed that the plots for the above-mentioned features displayed the same trend when compared to the results obtained in the previous sections under different operational conditions. This case under investigation has different vibration amplitude due to the effect of air injection in the flow pattern within a pump as well as the cavitation occurrence. It can be seen that trends for the mean and RMS vibration amplitudes values have small changes at flow rate between 100 and 350(1/min) for both cases (with and without air injection). However, the trends for the above-mentioned features for both cases are rapidly increased after flow rate of $350(1 / \mathrm{min})$. There are two possible reasons for this observation. The first is mostly due to the interaction between impeller/volute as well as 
cavitation occurrence within a pump. The second one is due to the amount of air injection which causes more instability in the flow pattern inside the pump and hence, leads to increasing pressure fluctuations in the pump due to more interactions between the air injection bubbles and the collapsed bubbles as a result of the cavitation process.

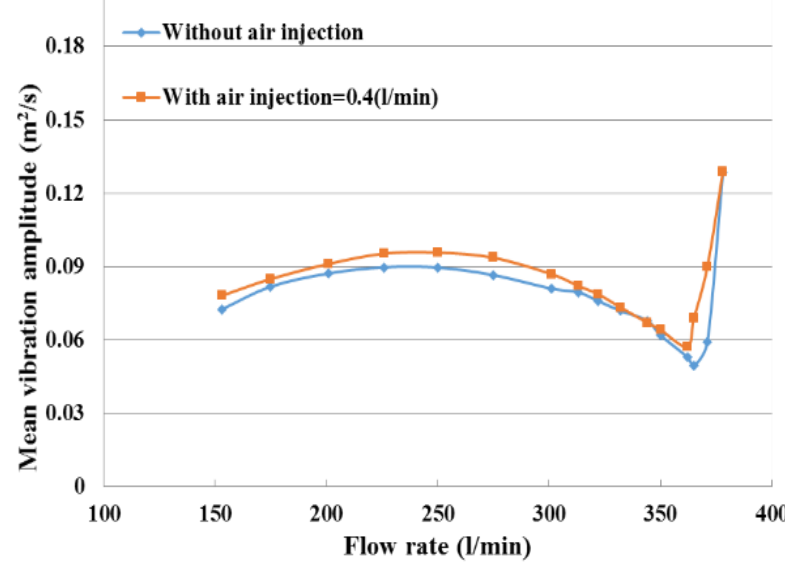

(a) $0 \mathrm{~Hz}-1 \mathrm{kHz}$

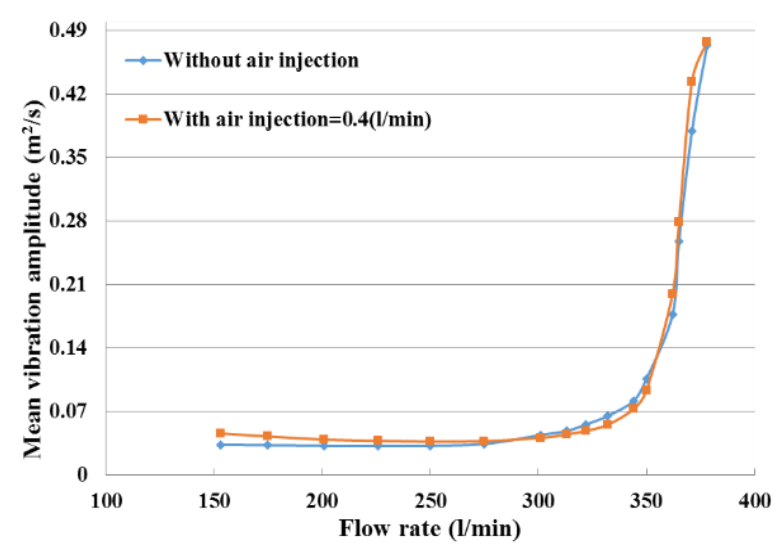

(c) $2 \mathrm{kHz}-10 \mathrm{kHz}$

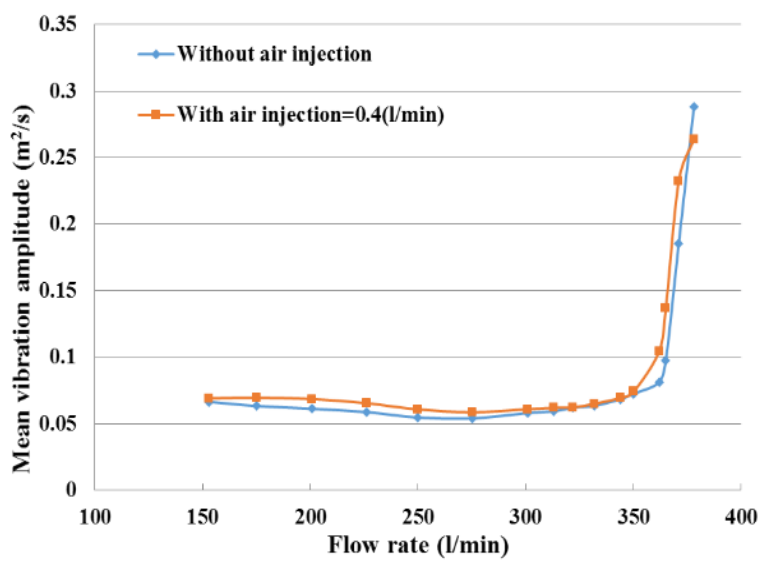

(b) $1 \mathrm{kHz}-2 \mathrm{kHz}$

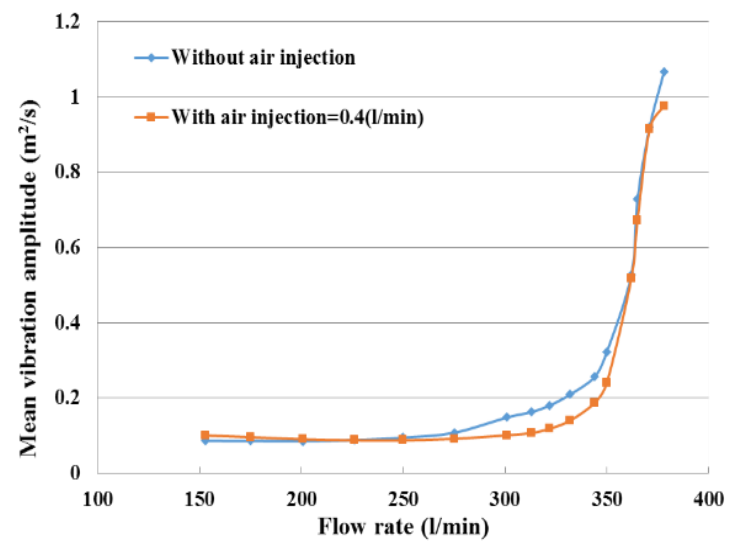

(d) $10 \mathrm{kHz}-15 \mathrm{kHz}$

Figure 7: Mean vibration amplitude value of the frequency range from $0 \mathrm{~Hz}$ to $15 \mathrm{kHz}$ at $2755 \mathrm{rpm}$ with and without air injection

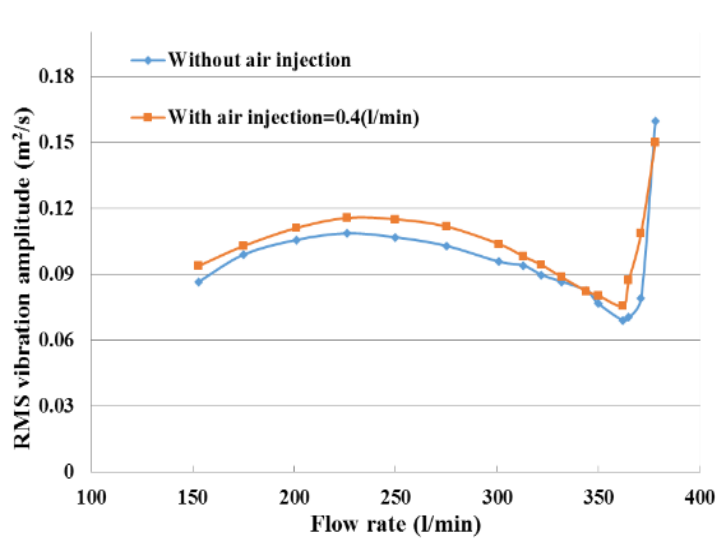

(a) $0 \mathrm{~Hz}-1 \mathrm{kHz}$

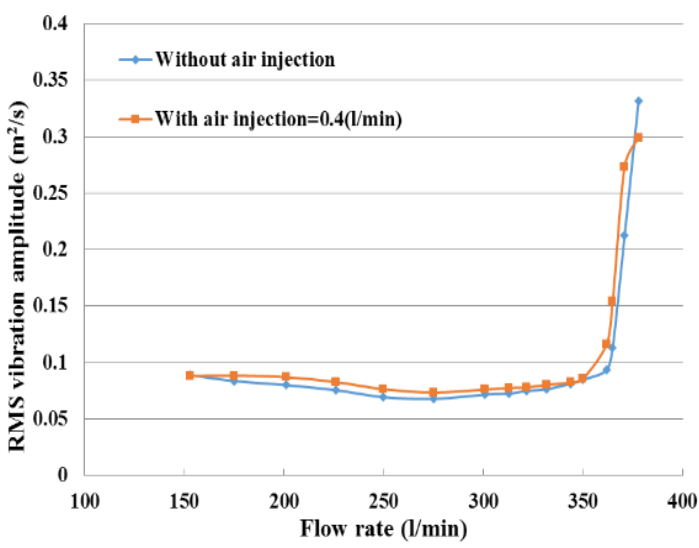

(b) $1 \mathrm{kHz}-2 \mathrm{kHz}$ 


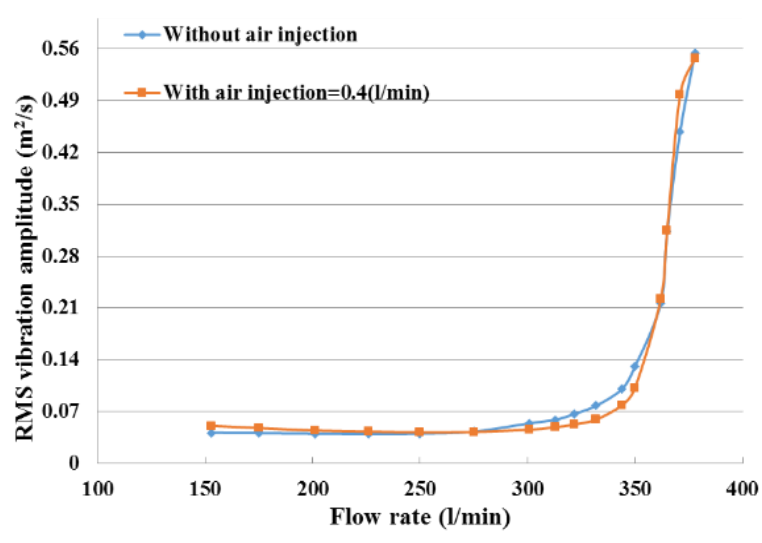

(c) $2 \mathrm{kHz}-10 \mathrm{kHz}$

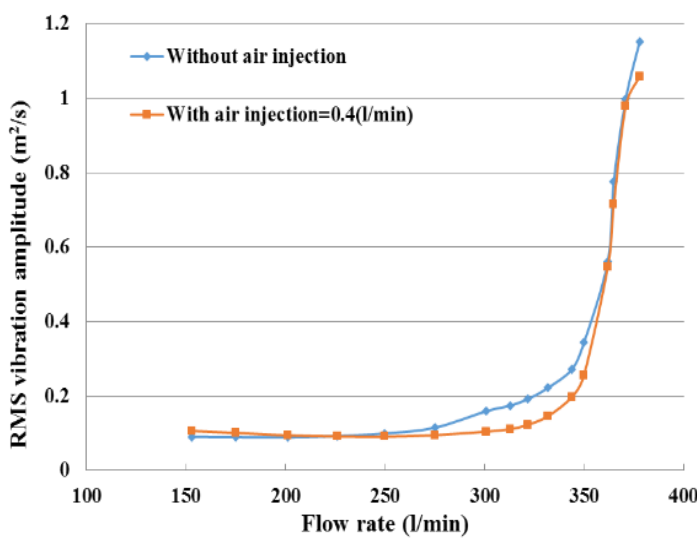

(d) $10 \mathrm{kHz}-15 \mathrm{kHz}$

Figure 8: RMS vibration amplitude value of the frequency range from $0 \mathrm{~Hz}$ to $15 \mathrm{kHz}$ at $2755 \mathrm{rpm}$ with and without air injection

\subsection{Calculation of the Head of the Centrifugal Pump at Different Air Injection Rates}

Figure 9 depicts the pump head under different flow rates and air injections. The amounts of air injection were $0.4,1$, and $1.8(1 / \mathrm{min})$ and $\mathrm{N}=2755 \mathrm{rmp}$. It can be seen that the head under both cases (with and without air injection) in the pump has a continuous downward trend with increasing flow rate. In addition, the results showed that the pump head was decreased with air injection increased when the pump operates under a flow rates. Due to hydraulic losses and additional losses caused by air injection bubbles and the second reason is due to more pressure fluctuations within a pump, which causes the formation and collapse of the bubbles from both the occurrence of cavitation and air injection.

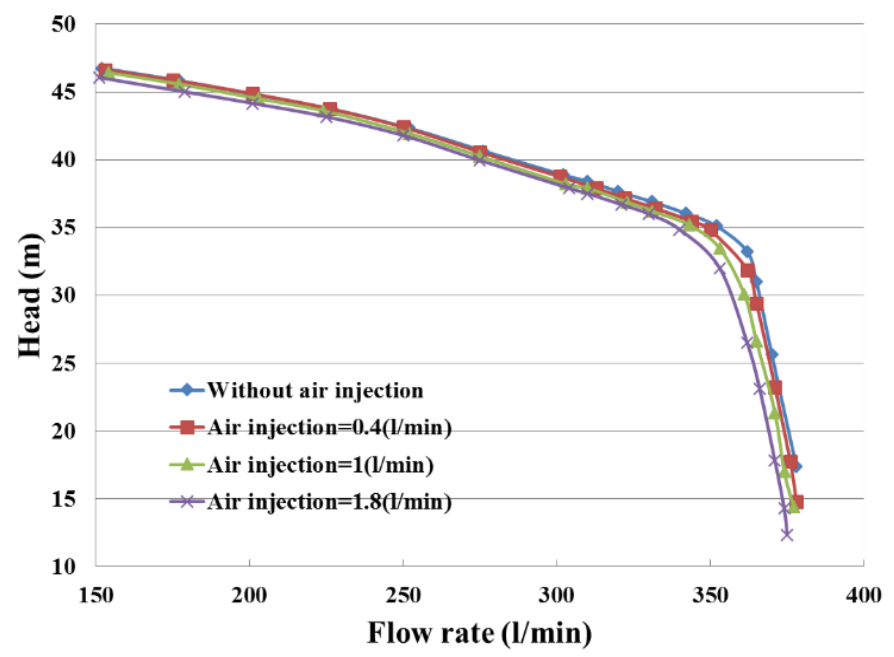

Figure 9: Head of the pump with and without air injection under different air injections 


\subsection{Time domain Analysis on the Vibration Signal for at Different Air Injection Rates}

For comparison purposes between the different cases the amounts of air injection were $0.4,1$, and $1.8(1 / \mathrm{min})$, in time domain analysis, all of the results that were obtained from the experimental setup for the centrifugal pump showed to follow the same trend for the peak, RMS, peak-to-peak and variance features as illustrated in Figure 10. These results indicated that no significant change occurs in the vibration amplitude at flow rate lower than $350(1 / \mathrm{min})$. However, the rapid increase in the vibration amplitude was at flow rate higher than $350(1 / \mathrm{min})$. This increase in the vibration amplitude can be explained due to the increase in the formation of bubbles that causes cavitation. The additional air bubbles lead to decrease in pressure at the eye of impeller, below the water vapour pressure. Hence, for this case, the NPSHA becomes lower than NPSHR value and at this point cavitation increases and then develops fully within the pump. Furthermore, high amount of air injection within the suction side of the pump can be collected back which forms a pocket around the impeller, particularly at the eye of the impeller which causes more losses in the pump and then possibly leading to air binding. As a result of air binding, problems such as the impeller spinning in the air occurs that may lead to increase in the pressure fluctuations and also increase in the heating of the pump. This can then lead to damage to the bearing, impeller and the volute of the pump.

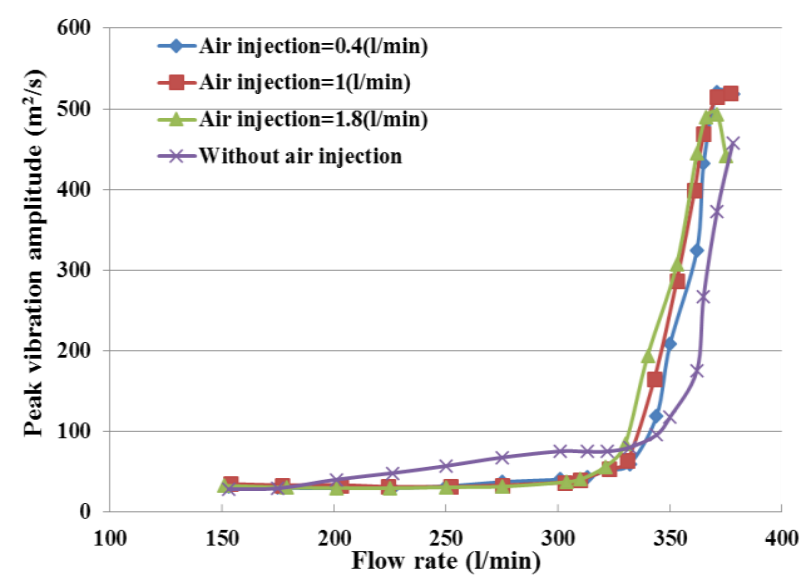

(a) Peak

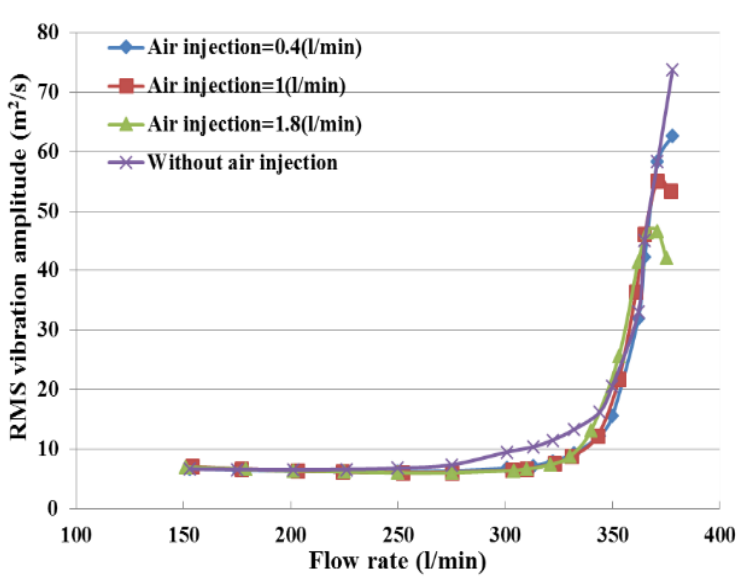

(b) RMS 


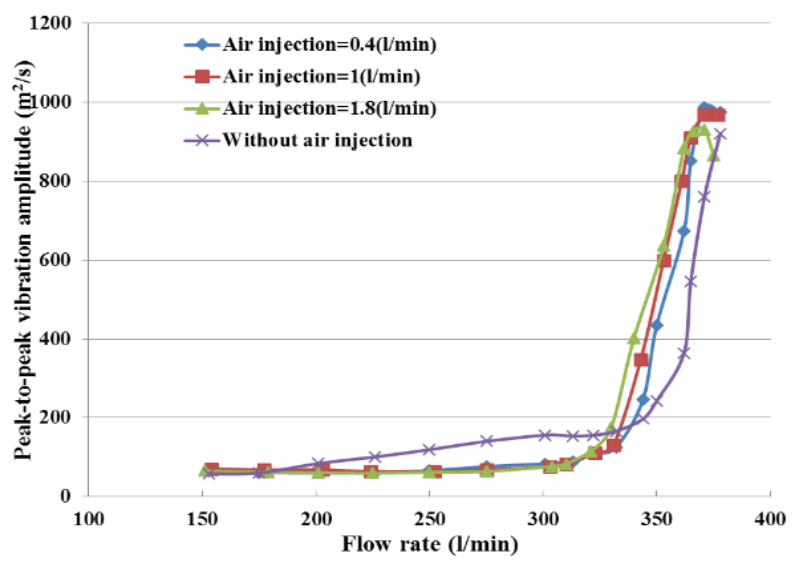

(c) Peak-to-peak

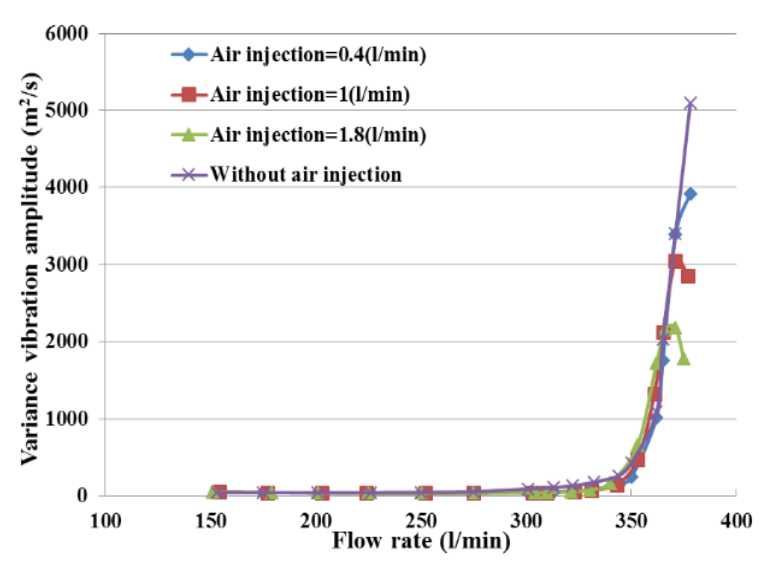

(d) Variance

Figure 10: Comparison between different statistical features of the vibration signals in time domain different air injections

For more results on the maximum peak, RMS, peak-to-peak and variance features of the pump, Tables 2 and 3 provide the comparison between above cases. The maximum and minimum values of peak and peak-to-peak for air injection 0.4(1/min) were higher than another case. The reasons for this is because the pressure fluctuations for air injection at $1(1 / \mathrm{min})$ are higher than air injection at $1.8(1 / \mathrm{min})$. Pressure fluctuations within the centrifugal pump are generated due to several reasons, which include interactions between the impeller (rotor) and volute (stator), especially at the volute tongue region. In addition, another reason is due to secondary flow together with the inner pump flow. Finally, the primary reason for this pressure fluctuation generation is the occurrence of cavitation and also due to the air injection within a pump.

Table 2: Summary of the maximum statistical features of the vibration amplitude in time domain at different air injections

\begin{tabular}{|c|c|c|c|c|}
\hline Air injection & Peak & RMS & Peak-to-peak & Variance \\
\hline$(1 / \mathrm{min})$ & $\left(\mathrm{m} / \mathrm{s}^{2}\right)$ & $\left(\mathrm{m} / \mathrm{s}^{2}\right)$ & $\left(\mathrm{m} / \mathrm{s}^{2}\right)$ & $\left(\mathrm{m} / \mathrm{s}^{2}\right)$ \\
\hline 0.4 & 520.44 & 62.65 & 989.39 & 3922.40 \\
\hline 1 & 537.20 & 55.17 & 992.52 & 3048.60 \\
\hline 1.8 & 493.38 & 46.69 & 930.52 & 2180.0 \\
\hline
\end{tabular}

Table 3: Summary of the minimum statistical features of the vibration amplitude in time domain at different air injections

\begin{tabular}{|c|c|c|c|c|}
\hline Air injection & Peak & RMS & Peak-to-peak & Variance \\
\hline$(1 / \mathrm{min})$ & $\left(\mathrm{m} / \mathrm{s}^{2}\right)$ & $\left(\mathrm{m} / \mathrm{s}^{2}\right)$ & $\left(\mathrm{m} / \mathrm{s}^{2}\right)$ & $\left(\mathrm{m} / \mathrm{s}^{2}\right)$ \\
\hline 0.4 & 29.27 & 6.13 & 59.75 & 37.60 \\
\hline
\end{tabular}




\begin{tabular}{|c|c|c|c|c|}
\hline 1 & 29.01 & 6.02 & 63.31 & 36.20 \\
\hline 1.8 & 28.22 & 6.01 & 59.19 & 36.0 \\
\hline
\end{tabular}

\subsection{Frequency Domain Analysis on the Vibration Signal at Different Air Injections}

Figure 11 depicts the vibration signals in frequency domain at different frequency ranges from $0 \mathrm{~Hz}-1 \mathrm{kHz}$ to $1 \mathrm{kHz}-2 \mathrm{kHz}$ under different flow rates, air injection 1 and $1.8(1 / \mathrm{min})$. It can be seen that there is no significant change in the level of amplitude of the vibration signals when the pump works at a capacity lower than $350(1 / \mathrm{min})$. However, a small increase in the level of amplitude of the vibration signal occurred at flow rate higher than $350(1 / \mathrm{min})$. It is also seen that dominant frequencies includes the rotation frequency and its harmonics, the BPF for all cases being investigation.

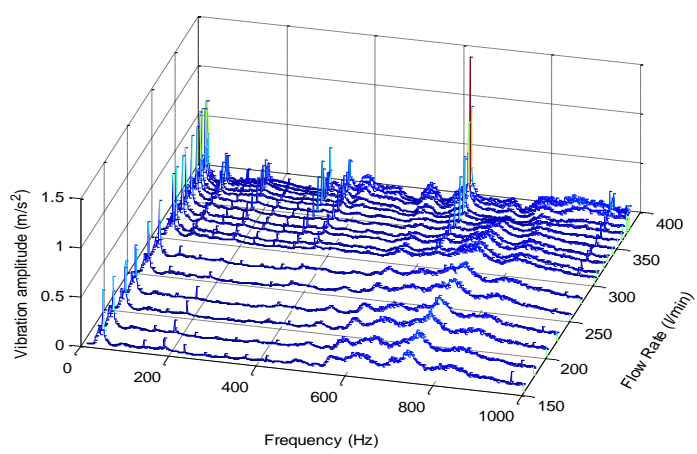

(a)

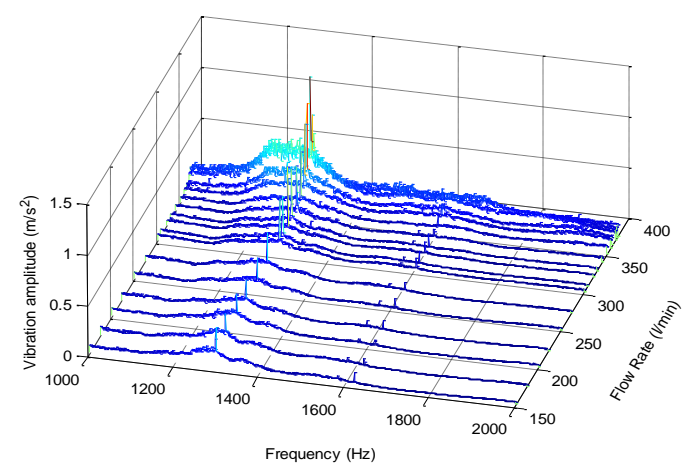

(b)

Figure 11: Vibration signal in frequency domain under various air injections and frequency range from (a) $0 \mathrm{~Hz}-1 \mathrm{kHz}$ to (b) $1 \mathrm{kHz}-2 \mathrm{kHz}$

For comparison purposes between the above cases $0.4,1$, and $1.8(1 / \mathrm{min})$, in frequency domain analysis, all of the results that were obtained from the experimental setup under different air injection rates. The mean and RMS vibration amplitude features follow the same trend as depicted in Figures 12 and 13. These results indicated that no significant change occurs in the vibration amplitude at flow rate lower than $350(1 / \mathrm{min})$. The rapid increase in the vibration amplitude was at flow rate higher than $350(1 / \mathrm{min})$. This increase in the vibration amplitude due to the increase in the formation of bubbles that causes cavitation. The additional air bubbles lead to decrease in pressure at the eye of impeller, below the water vapour pressure. Furthermore, high amount of air injection within the suction side of the centrifugal pump can be collected back, which forms a pocket around the impeller, particularly at the eye of the impeller which causes more losses in the pump and then possibly leading to air binding. 


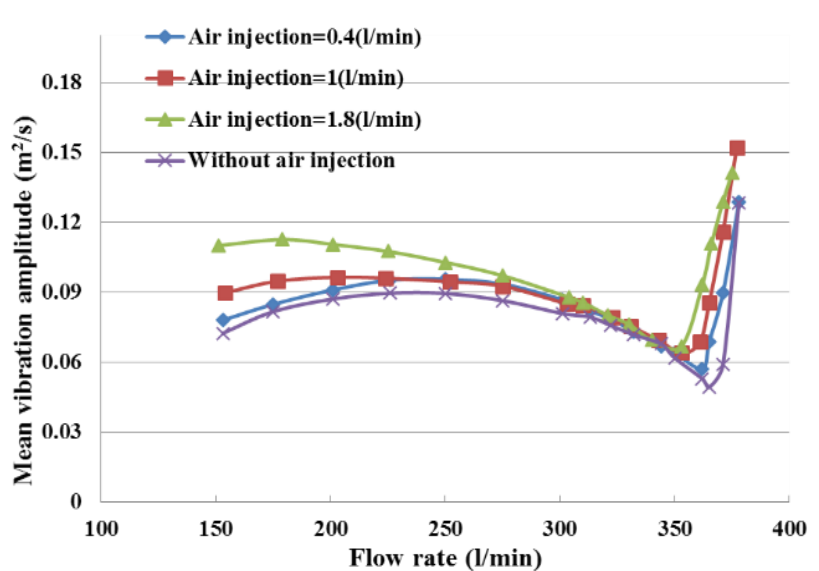

(a) $0 \mathrm{~Hz}-1 \mathrm{kHz}$

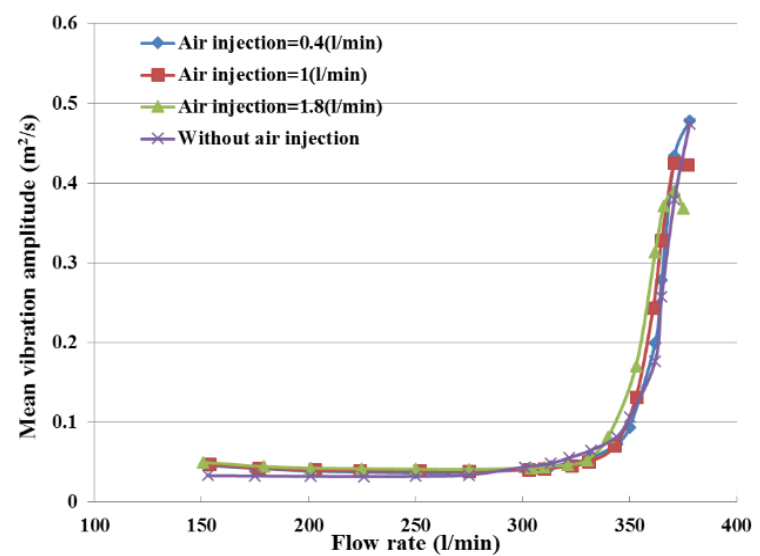

(c) $2 \mathrm{kHz}-10 \mathrm{kHz}$

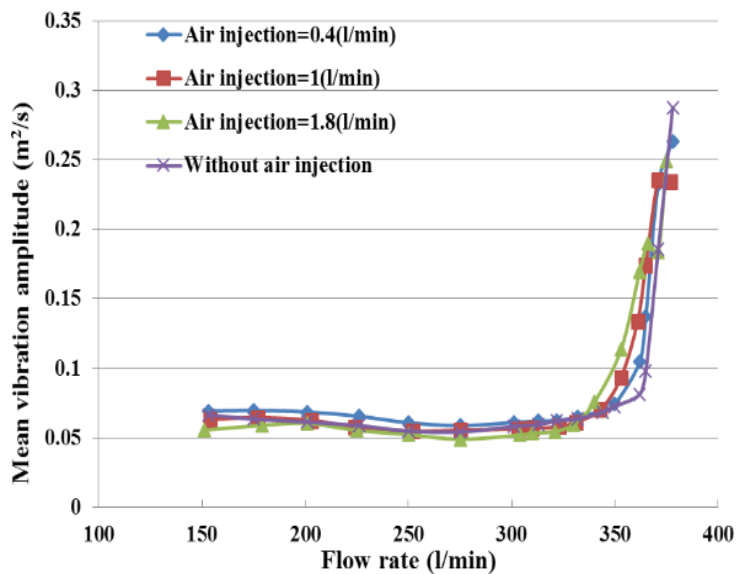

(b) $1 \mathrm{kHz}-2 \mathrm{kHz}$

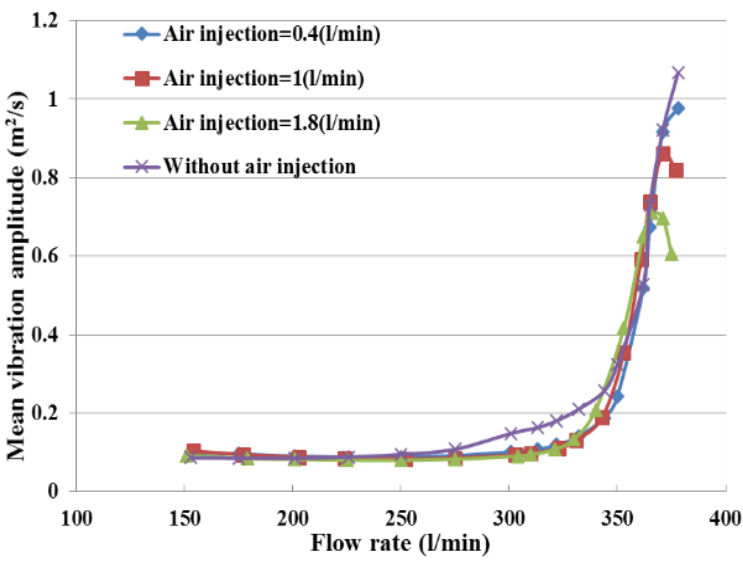

(d) $10 \mathrm{kHz}-15 \mathrm{kHz}$

Figure 12: Comparison between mean vibration amplitude values in frequency domain for different frequency ranges under different air injections

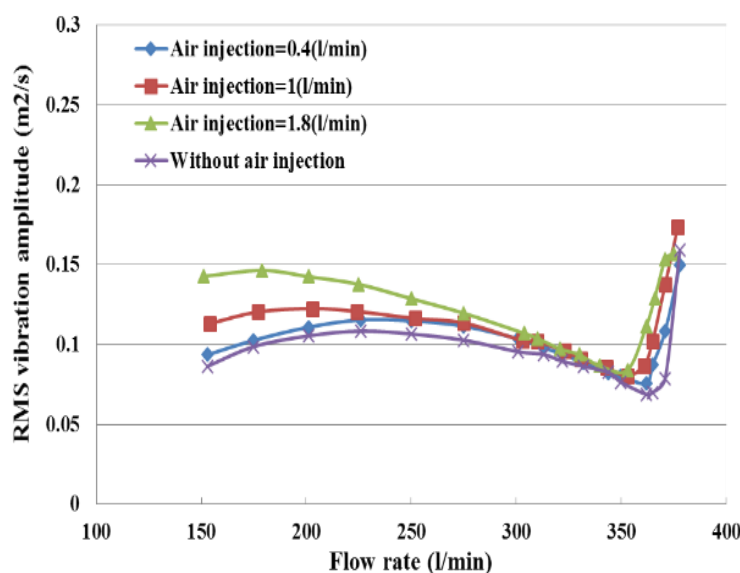

(a) $0 \mathrm{~Hz}-1 \mathrm{kHz}$

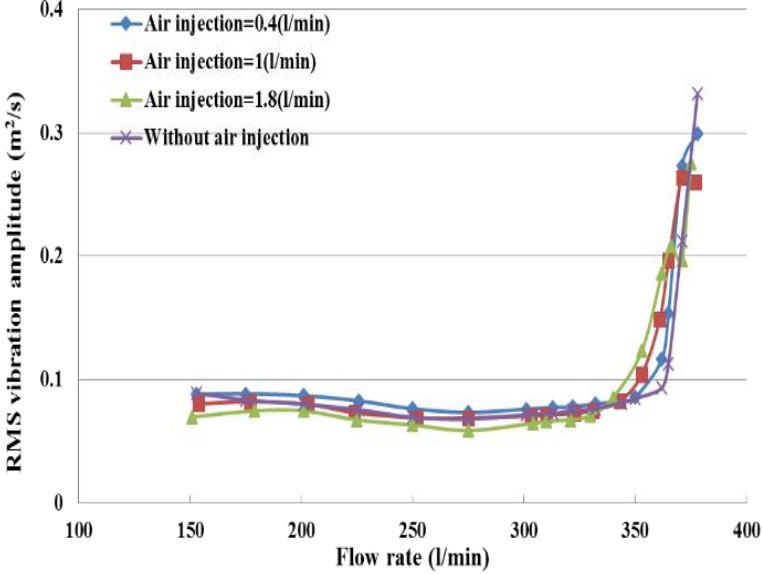

(b) $1 \mathrm{kHz}-2 \mathrm{kHz}$ 


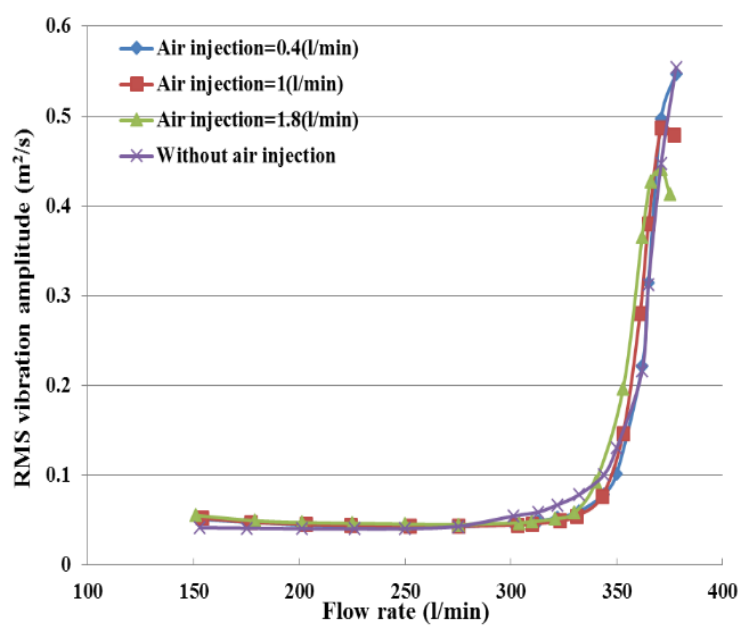

(c) $2 \mathrm{kHz}-10 \mathrm{kHz}$

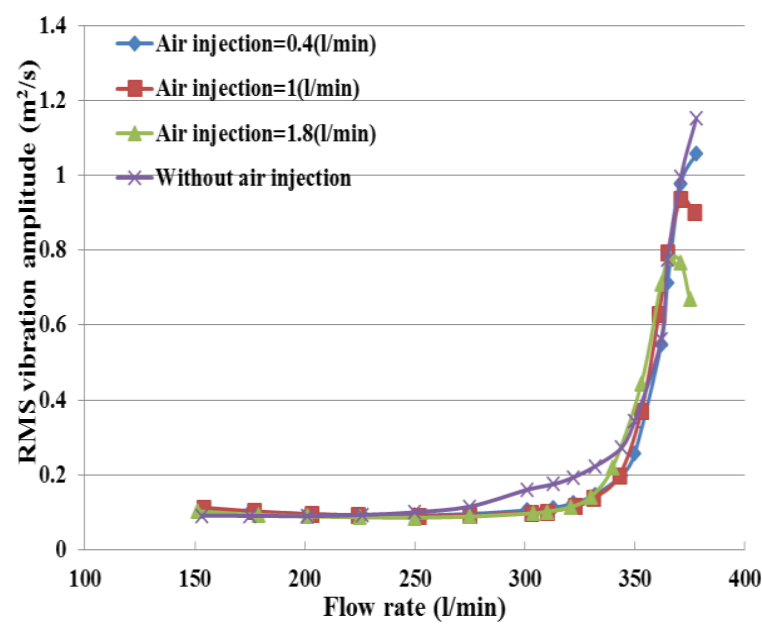

(d) $10 \mathrm{kHz}-15 \mathrm{kHz}$

Figure 13: Comparison between RMS vibration amplitude values in frequency domain for different and frequency ranges under different air injections

The maximum mean and RMS vibration amplitude values for air injection at $0.4(1 / \mathrm{min})$ were higher than for air injection at 1 and $1.8(1 / \mathrm{min})$ under the different range of frequencies as summarised in Tables 4 and 5.

Table 4: Summary of the results for the maximum mean vibration amplitude under different air injection and for $0 \mathrm{~Hz}-15 \mathrm{kHz}$

\begin{tabular}{|c|c|c|c|c|}
\hline Air injection & $\begin{array}{c}\text { Mean value } \\
0 \mathrm{~Hz}-1 \mathrm{kHz}\end{array}$ & $\begin{array}{c}\text { Mean value } \\
1 \mathrm{kHz}-2 \mathrm{kHz}\end{array}$ & $\begin{array}{c}\text { Mean value } \\
2 \mathrm{kHz}-10 \mathrm{kHz}\end{array}$ & $\begin{array}{c}\text { Mean value } \\
10 \mathrm{kHz}-15 \mathrm{kHz}\end{array}$ \\
\hline$(1 / \mathrm{min})$ & $\left(\mathrm{m} / \mathrm{s}^{2}\right)$ & $\left(\mathrm{m} / \mathrm{s}^{2}\right)$ & $\left(\mathrm{m} / \mathrm{s}^{2}\right)$ & $\left(\mathrm{m} / \mathrm{s}^{2}\right)$ \\
\hline 0.4 & 0.1287 & 0.2681 & 0.4811 & 0.9766 \\
\hline 1 & 0.1220 & 0.2417 & 0.4283 & 0.8611 \\
\hline 1.8 & 0.1413 & 0.2492 & 0.3902 & 0.7098 \\
\hline
\end{tabular}

Table 5: Summary of the results for the maximum RMS vibration amplitude under different air injection and for $0 \mathrm{~Hz}-15 \mathrm{kHz}$

\begin{tabular}{|c|c|c|c|c|}
\hline Air injection & $\begin{array}{c}\text { RMS value } \\
0 \mathrm{~Hz}-1 \mathrm{kHz}\end{array}$ & $\begin{array}{c}\text { RMS value } \\
1 \mathrm{kHz}-2 \mathrm{kHz}\end{array}$ & $\begin{array}{c}\text { RMS value } \\
2 \mathrm{kHz}-10 \mathrm{kHz}\end{array}$ & $\begin{array}{c}\text { RMS value } \\
10 \mathrm{kHz}-15 \mathrm{kHz}\end{array}$ \\
\hline$(1 / \mathrm{min})$ & $\left(\mathrm{m} / \mathrm{s}^{2}\right)$ & $\left(\mathrm{m} / \mathrm{s}^{2}\right)$ & $\left(\mathrm{m} / \mathrm{s}^{2}\right)$ & $\left(\mathrm{m} / \mathrm{s}^{2}\right)$ \\
\hline 0.4 & 0.1497 & 0.3081 & 0.5490 & 1.0585 \\
\hline 1 & 0.1437 & 0.2673 & 0.4869 & 0.9365 \\
\hline 1.8 & 0.1431 & 0.2660 & 0.4416 & 0.7809 \\
\hline
\end{tabular}




\section{Conclusions}

Based on the above results in this section, several conclusions can be drawn regarding air injection within a pump and are listed below.

1. The head under both cases (with and without air injection) in the pump follow a continuous downward trend with increasing flow rate.

2. The results showed that there is no significant change in the pump head for both cases (with and without air injection), when the pump works lower than low flow rate at low amount of air injection.

3. Analysis on the vibration signals using time wave form showed that there is difference in the level of vibration amplitudes when the pump operates at normal conditions (without cavitation) and under cavitation conditions with air injection.

4. The analysis on the vibration signals in time domain using peak, RMS, peak-to- peak and variance features, with and without air injection, showed that there is a small indication of variance in the vibration level at flow rates below 350(1/min). However, the vibration level witnesses a significant rapid increase when the centrifugal pump operates at flow rate higher than $350(1 / \mathrm{min})$.

5. Analysis on the vibration signals in frequency domain, under different amounts of air injection, revealed different types of frequencies. The first one was the rotational frequency and the second was the BPF and their harmonics.

6. The vibration amplitudes increase with an increase in the flow rate due to the occurrence of the inception and development of cavitation in the pump.

7. The use of frequency domain to analyse the vibration signal, is a suitable technique to study the effect of air injection in the pump and also to detect the inception and development of cavitation.

8. Analysing vibration signals in frequency domain using mean and RMS vibration amplitude features showed that the trends for these features have slight changes where flow rate is between 100 and 350(1/min) under both cases (with and without air injection). However, the trends for the above features under both cases rapidly increase after 350(1/min).

9. The trend for the vibration amplitude for both features (mean and RMS) with air injection at a frequency range starting from $2 \mathrm{kHz}$ to high-frequency of $15 \mathrm{kHz}$ slightly decreases at high flow, but the vibration amplitude without air injection increases with an increase in flow rate. 


\section{Acknowledgements}

The author would like to thank Mustansiriyah University (www.uomustansiriyah.edu.iq) Baghdad - Iraq for its support in the present work. The author also would like to gratefully acknowledge the financial support by the Ministry of Higher Education and Scientific Research (Iraq). The measurement data was a part of author PhD degree at University of Huddersfield (UK). As well, the author would like to thank their support and collaboration.

\section{References}

1. Al-Obaidi, A.. Experimental and Numerical Investigations on the Cavitation Phenomenon in a Centrifugal Pump (Doctoral dissertation, University of Huddersfield). (2018).

2. Al-Obaidi, A. R. Monitoring the performance of centrifugal pump under single-phase and cavitation condition: A CFD analysis of the number of impeller blades. Journal of Applied Fluid Mechanics, 12(2), 445-459. (2019).

3. Al-Obaidi, A. R. Effects of different turbulence models on three-dimensional unsteady cavitating flows in the centrifugal pump and performance prediction. International Journal of Nonlinear Sciences and Numerical Simulation, 20(3-4), 487-509. (2019).

4. Lobanoff, V. S., \& Ross, R. R. Centrifugal pumps: design and application. Elsevier. (2013).

5. Al-Obaidi, A. R. Monitoring the performance of centrifugal pump under single-phase and cavitation condition: A CFD analysis of the number of impeller blades. Journal of Applied Fluid Mechanics, 12(2), 445-459. (2019).

6. Tuzson, J. Centrifugal pump design. John Wiley \& Sons. (2000).

7. Schmitz, S. Reducing pump noise in cooling tower applications. World pumps, (456), 2429. (2004).

8. Chudina, M. Noise as an indicator of cavitation in a centrifugal pump. Acoustical Physics, 49(4), 463-474. (2003).

9. Černetič, J., Prezelj, J., \& Čudina, M. Use of noise and vibration signal for detection and monitoring of cavitation in kinetic pumps. The Journal of the Acoustical Society of America, 123(5), 3316-3316. (2008).

10. Čdina, M. Detection of cavitation phenomenon in a centrifugal pump using audible sound. Mechanical systems and signal processing, 17(6), 1335-1347. (2003).

11. Čudina, M., \& Prezelj, J. Detection of cavitation in operation of kinetic pumps. Use of discrete frequency tone in audible spectra. Applied Acoustics, 70(4), 540-546. (2009).

12. Nasiri, M. R., Mahjoob, M. J., \& Vahid-Alizadeh, H. Vibration signature analysis for detecting cavitation in centrifugal pumps using neural networks. In Mechatronics (ICM), 2011 IEEE International Conference on (pp. 632-635). (2011).

13. Al-Obaidi, A. R. Investigation of effect of pump rotational speed on performance and detection of cavitation within a centrifugal pump using vibration analysis. Heliyon, 5(6), e01910. (2019).

14. Al-Obaidi, A. R. Experimental investigation of the effect of suction valve opening on the performance and detection of cavitation in the centrifugal pump based on acoustic analysis technique. Archives of Acoustics, 44. (2019). 
15. Al-Obaidi, A. R., \& Towsyfyan, H. An Experimental Study on Vibration Signatures for Detecting Incipient Cavitation in Centrifugal Pumps Based on Envelope Spectrum Analysis. Journal of Applied Fluid Mechanics, 12(6), 2057-2067. (2019).

16. Kamiel, B. P. Vibration-based multi-fault diagnosis for centrifugal pumps (Doctoral dissertation, Curtin University). (2015).

17. Zhang, N., Yang, M., Gao, B., \& Li, Z. Vibration characteristics induced by cavitation in a centrifugal pump with slope volute. Shock and Vibration, (2015).

18. Buono, D., Siano, D., Frosina, E., \& Senatore, A. Gerotor pump cavitation monitoring and fault diagnosis using vibration analysis through the employment of auto-regressivemoving-average technique. Simulation Modelling Practice and Theory, 71, 61-82.2017) ).

19. Casoli, P., Pastori, M., Scolari, F., \& Rundo, M. A vibration signal-based method for fault identification and classification in hydraulic axial piston pumps. Energies, 12(5), 953. 2019)).

20. Lu, J., Liu, X., Zeng, Y., Zhu, B., Hu, B., Yuan, S., \& Hua, H. Detection of the Flow State for a Centrifugal Pump Based on Vibration. Energies, 12(16), 3066.2019) ).

21. Mousmoulis, G., Yiakopoulos, C., Kassanos, I., Antoniadis, I., \& Anagnostopoulos, J. Vibration and acoustic emission monitoring of a centrifugal pump under cavitating operating conditions. In IOP Conference Series: Earth and Environmental Science (Vol. 405, No. 1, p. 012003). IOP Publishing.2019)).

22. Brennen, C. E. Hydrodynamics of pumps. Concepts ETI Inc., Oxford Science Publications, 81. (1994).

23. Bachus, L., \& Custodio, A. (Eds.). Know and understand centrifugal pumps. Elsevier. (2003).

24. Al-Obaidi, A. R. Detection of Cavitation Phenomenon within a Centrifugal Pump Based on Vibration Analysis Technique in both Time and Frequency Domains. Experimental Techniques, 1-19. (2020)

25. Gautam, N. Construction, Working And Advantages Of Centrifugal Pump. (2012), 